\title{
Is it time to make regular cardiopulmonary resuscitation training mandatory for all New Zealand registered physiotherapists?
}

\section{CARDIOPULMONARY RESUSCITATION (CPR) SAVES LIVES}

Cardiopulmonary resuscitation (CPR) is the technique of chest compressions combined with rescue breathing that has been clearly shown to save lives (Australian and New Zealand Committee on Resuscitation, 2016b). Health professionals play a vital role in ensuring the performance of all links of the cardiac arrest Chain of Survival (Figure 1) occur in a timely and proficient manner (Nolan, Soar, \& Eikeland, 2006). A recent survey of New Zealand registered physiotherapists identified that $20 \%$ of participants had used CPR in an emergency (Harvey, O'Brien, Moran, \& Webber, 2019). With the knowledge that our population is ageing and that patients are often presenting with more concurrent complex health conditions, this figure could increase in the future. While many physiotherapists hold CPR certification due to employment or contractual requirements, currently CPR certification is not mandatory for all physiotherapists practising in New Zealand (Physiotherapy Board of New Zealand, 2018). In their survey, Harvey et al. (2019) found over three-quarters of physiotherapists who responded to the survey believed CPR training should be mandatory. These factors led us to raise the question: Is it time to make regular cardiopulmonary resuscitation training mandatory for all New Zealand registered physiotherapists?

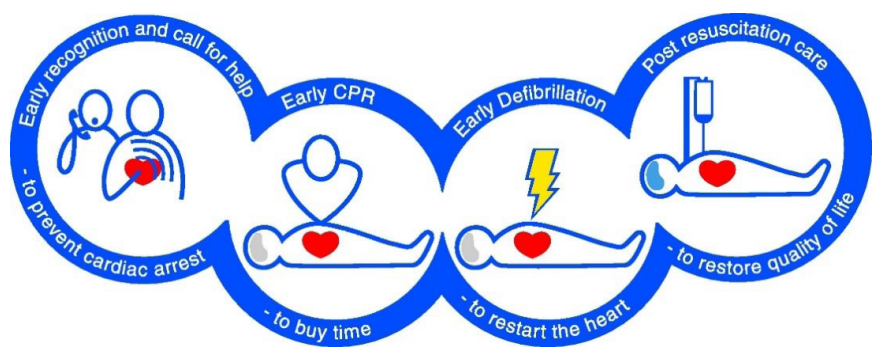

\section{Figure 1: The cardiac arrest Chain of Survival}

Copyright 2015 by Laerdal Medical. Reprinted with permission.

\section{PATIENT SAFETY}

The New Zealand Physiotherapy Standards Framework states that all physiotherapists must incorporate safety and risk management strategies within physiotherapy practice to ensure the safety of patients and staff (Physiotherapy Board of New Zealand, 2018). However, the only area of physiotherapy practice that specifically requires CPR certification is in the sports environment where individuals receive sports physiotherapy services. The framework states that "sports physiotherapists must hold up-to-date competencies in basic life support and management of acute trauma situations" (Physiotherapy Board of New Zealand, 2018, p. 80). Surprisingly, the recent survey of New Zealand physiotherapists found that clinicians working in private practice, public hospitals and community settings were more likely to have CPR certification compared to those working with sports teams (Harvey et al., 2019).
Harvey et al. (2019) reported that about half (56\%) of respondents had completed formal CPR training in the 12 months before participating in the survey. Conversely, the New Zealand Resuscitation Council recommends repeated refresher training for individuals who are not performing resuscitation regularly - stating that individuals should refresh their CPR skills annually (Australian and New Zealand Resuscitation Committee on Resuscitation, 2013). In contrast to registered physiotherapists, final year physiotherapy students at both Auckland University of Technology and the University of Otago must gain CPR certification to take part in clinical placements. Having regular CPR training would ensure all New Zealand physiotherapists are prepared to respond in an emergency in a safe, competent, and accountable manner.

\section{A DUTY OF CARE}

Of the 688 New Zealand physiotherapists recently surveyed, 97\% agreed with the following statement: "At work, it is my duty to intervene and perform CPR in an emergency" (Harvey et al., 2019, p. 98). A duty of care is a legal obligation to provide a reasonable standard of professional care to patients, and to act in a way to protect and maintain their safety. Once a health professional has accepted a patient into his or her care, that health professional has a duty of care to that person (Johnson \& O'Brien, 2010). The New Zealand Physiotherapy Standards Framework (Physiotherapy Board of New Zealand, 2018) does not explicitly address the duty of care of physiotherapists in an emergency.

The Physiotherapy Board of Australia Code of Conduct (2014) states that when Australian registered physiotherapists are treating patients in an emergency:

Good practise involves offering assistance in an emergency that takes account of the practitioner's own safety, skills, the availability of other options and the impact on any other patients or clients under the practitioner's care, and continuing to provide that assistance until services are no longer required. (p. 9)

Within the New Zealand Physiotherapy Standards Framework (Physiotherapy Board of New Zealand, 2018) are the New Zealand and Australia physiotherapy practice thresholds which "describe the threshold competence required for initial and continuing registration as a physiotherapist in both Australia and Aotearoa New Zealand" (p. 93). There is an opportunity to align the duty of care of New Zealand physiotherapists with Australian physiotherapists when responding to a patient in an emergency.

\section{CPR IS ONLY PART OF THE PICTURE: WHERE IS THE NEAREST DEFIBRILLATOR?}

Access to an automated external defibrillator (AED) dramatically increases the chances of survival during a cardiac event. Following early CPR as in the Chain of Survival, the time to defibrillation is a crucial factor that influences survival. For every 
minute defibrillation is delayed, there is approximately a $10 \%$ reduction in survival if the victim is in cardiac arrest due to ventricular fibrillation (Australian and New Zealand Resuscitation Committee, 2016a). Hence, it is crucial to know the location of the nearest accessible AED and how to use it correctly. Harvey et al. (2019) found physiotherapists older than 39 years of age were more likely to be incorrect to specific AED knowledge questions than younger physiotherapists. Modern technology has made locating AEDs easier with mobile phone applications that can put this information in the palm of your hand. Two such phone applications in New Zealand are AED Locations (https://www.aedlocations.co.nz) and GoodSAM (https://www. stjohn.org.nz/First-Aid/goodsam/). If regular trainings and a response plan is in place, AEDs can be effective in public settings and places of work where witnessed cardiac arrest can occur (Australian and New Zealand Resuscitation Committee, 2016b).

\section{CONCLUSION}

New Zealand registered physiotherapists are exposed to situations that require CPR at rates much higher than the general population. Furthermore, it is our opinion that physiotherapists have a duty of care to their patients to be competent in CPR to ensure patient safety. We believe that registered physiotherapists should offer themselves to assist in an emergency to the level of their training. We would therefore value the Physiotherapy Board of New Zealand entering into a discussion with the profession to review the current CPR training requirements for New Zealand registered physiotherapists.

Daniel Harvey MHSc (Hons), MHPrac (Dist), BHSc (Physio) Managing Director, Sports \& Spinal Physiotherapy, Westgate, Auckland, New Zealand

Daniel O’Brien PhD, MHSc (Hons), BHSc (Physio)

Senior Lecturer, Department of Physiotherapy, School of Clinical Sciences, Auckland University of Technology, Auckland, New Zealand

Diana Horner MHSc (Hons), BHSc Physio (Hons) Senior Lecturer, Department of Physiotherapy, School of Clinical Sciences, Auckland University of Technology, Auckland, New Zealand

\section{ADDRESS FOR CORRESPONDENCE}

Daniel Harvey, Managing Director, Sports \& Spinal Physiotherapy, PO Box 84-079 Westgate, Auckland, 0657, New Zealand. Tel: +649833 6722. Email: daniel@sportsandspinal.co.nz

\section{PERIMISSIONS}

Written permission for reproduction of Figure 1 in the New Zealand Journal of Physiotherapy was obtained from Laerdal Medical.

\section{REFERENCES}

Australian and New Zealand Committee on Resuscitation. (2016a). ANZCOR guideline 7 - Automated external defibrillation in basic life support. Retrieved from: https://www.nzrc.org.nz/assets/Guidelines/BLS/ANZCORGuideline-7-AED-Jan16.pdf

Australian and New Zealand Committee on Resuscitation. (2016b). ANZCOR guideline 8 - Cardiopulmonary resuscitation (CPR). Retrieved from: https:// www.nzrc.org.nz/assets/Guidelines/BLS/ANZCOR-Guideline-8-CPR-Jan16. pdf

Australian and New Zealand Committee on Resuscitation. (2013). Guideline 10.1 - Basic life support training. Retrieved from: https://www.nzrc.org.nz/ assets/Guidelines/EIT/Guideline10.1March2013.pdf

Harvey, D., O’Brien, D., Moran, K., \& Webber, J. (2019). Knowledge and perceptions of cardiopulmonary resuscitation amongst New Zealand physiotherapists. New Zealand Journal of Physiotherapy, 47(2), 94-105. https://12218-console.memberconnex.com/Folder?Action=View\%20 File\&Folder_id=454\&File=NZJP\%20Vol\%2047\%20Number\%202_04_ final.pdf

Johnson, S., \& O'Brien, A. (2010). Liability for personal injury. In Keenan, R (Ed.), Health care and the law (4th ed., pp.149-198). Thompson Reuters.

Nolan, J., Soar, J., \& Eikeland, H. (2006). The chain of survival. Resuscitation, 71(3), 270-271. https://doi.org/10.1016/j.resuscitation.2006.09.001

Physiotherapy Board of Australia. (2014). Code of conduct. Retrieved from: https://www.physiotherapyboard.gov.au/Codes-Guidelines/Code-ofconduct.aspx

Physiotherapy Board of New Zealand. (2018). Physiotherapy standards framework. Retrieved from: https://www.physioboard.org.nz/sites/default/ files/Physiotherapy-Board-Code-Standards-Thresholds.pdf 